\title{
The albedo properties of four clean stratocumulus clouds studied during the VOCALS-REX field campaign
}

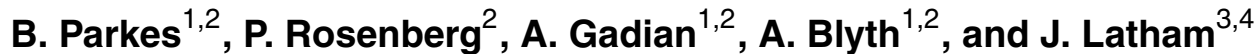

${ }^{1}$ NCAS, School of Earth and Environment, The University of Leeds, UK

${ }^{2}$ ICAS, School of Earth and Environment, The University of Leeds, UK

${ }^{3}$ School of Earth, Atmospheric and Environmental Sciences, The University of Manchester, UK

${ }^{4}$ MMM, UCAR, Boulder Colorado, USA

Received: 26 October 2012 - Accepted: 9 November 2012 - Published: 21 November 2012

Correspondence to: B. Parkes (b.parkes@see.leeds.ac.uk)

Published by Copernicus Publications on behalf of the European Geosciences Union.
Albedo properties of clouds observed during VOCALS-REx

B. Parkes et al.

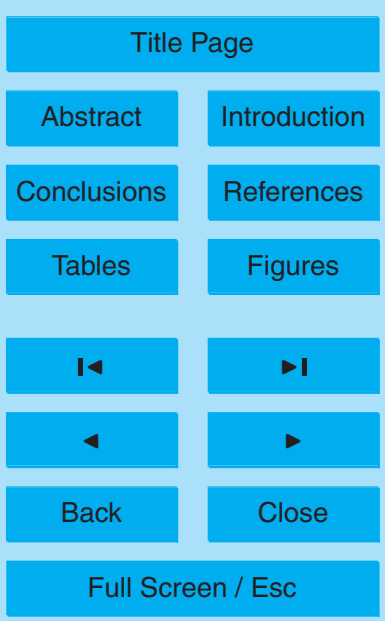

Printer-friendly Version

Interactive Discussion 


\section{Abstract}

The VOCALS-REx field campaign which took place in 2008 used several platforms to investigate the persistent marine stratocumulus cloud deck off the Chilean and Peruvian coasts. VOCALS-UK was the UK component of the experiment, during which the

5 FAAM BAe-146 aircraft gathered data in the stratocumulus cloud. It flew 13 research flights including investigations along $20^{\circ} \mathrm{S}$ transects.

In this paper, the shortwave cloud albedo derived from the Cloud Droplet Probe is compared with the albedo measured from two shortwave radiometers. Four clean cloud segments were selected for investigation. The suitability of the $\delta$-Eddington approxima-

10 tion as a method of calculating shortwave albedo is investigated and it is found to be acceptable (with a $R^{2}$ of 0.78 ) for solar zenith angles below 65 degrees.

\section{Introduction}

Marine stratocumulus clouds are known to have a significant impact on the climate system, reflecting up to $30 \%$ of the solar radiation incident on the Earth (Borg and

15 Bennartz, 2007) They are regularly found off the coasts of Peru, California and Angola (Hanson, 1991). The ability to assess the albedo of clouds using microphysics enables more detailed investigation of marine stratocumulus clouds using a single platform.

The stratocumulus deck found in the southeast Pacific was investigated by the VOCALS-REx field campaign in 2008 (Wood et al., 2011). The campaign involved the NCAR C-130, the UK FAAM BAe-146, the UK Dornier 228 and the CIRPAS Twin Otter. The Ronald $\mathrm{H}$. Brown and the IMARPE R/V José Olaya were also involved. Ground based observations included surface and atmosphere measurements from Paposo (two sites), Paranal and lqueque. Data from the UK's BAe-146-301 Atmospheric

25 Research Aircraft operated by the Faculty for Airborne Atmospheric Measurements (FAAM). It will henceforth be called the FAAM BAe-146.

\section{Albedo properties of clouds observed during VOCALS-REx}

B. Parkes et al.

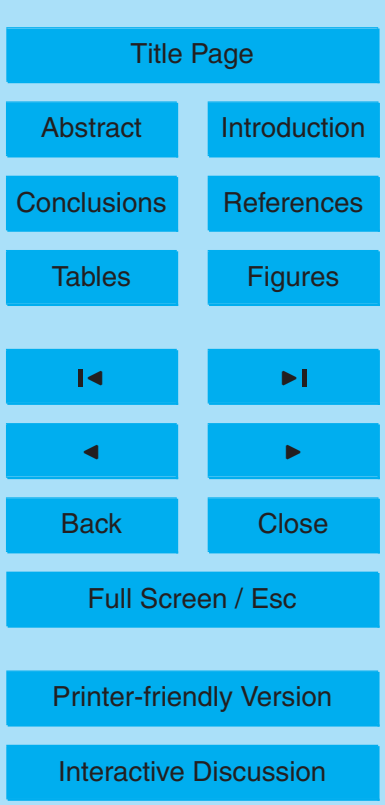


Much of the investigation of the southeast Pacific stratocumulus cloud deck was performed using flight paths along $20^{\circ} \mathrm{S}$, where it was found that air parcels further from the coast generally contained lower cloud droplet numbers and were more prone to drizzle formation (Bretherton et al., 2010). The impact of cellular convection on clouds 5 has been investigated in Wang et al. (2010), where it was suggested that cellular convection leads to increased precipitation rate and a reduced cloud albedo.

The Eddington approximation of albedo is an approximation based on a two stream approach. The $\delta$-Eddington is an expanded version of the Eddington approximation which improves the results at low solar zenith angles, where the cosine of the angle is 10 close to 1 . Both the Eddington and $\delta$-Eddington approximations are weaker at higher solar zenith angles and break down where the cosine of the solar zenith angle is below 0.4 (Joseph et al., 1976). The Eddington approximation described in Meador and Weaver (1980) was used by Twohy et al. (2005) to investigate the radiative properties of clouds from the DYCOMS-II experiment using data from the NCAR C-130 where the cloud albedo was found to be strongly influenced by aerosol content. The cloud albedo was also investigated using a simplified two stream approximation in Roberts et al. (2008) where aerosol loadings in clouds were shown to increase the microphysical albedo.

Calculation of the cloud albedo in this work has been performed using methods based on the $\delta$-Eddington approximation (Van-Weele and Duynkerke, 1993; Joseph et al., 1976). The work in Van-Weele and Duynkerke (1993) is combined with the cloud optical thickness and liquid water path approximations in Los and Duynkerke (2001) to produce a method suitable for use with aircraft data (See Equations 1 and 2 and discussion later). All times used in this paper are UTC. Local time is UTC-4 h. All
altitudes are given in altitude above mean sea level (MSL), unless otherwise stated.

\section{Albedo properties of clouds observed during VOCALS-REx}

B. Parkes et al.

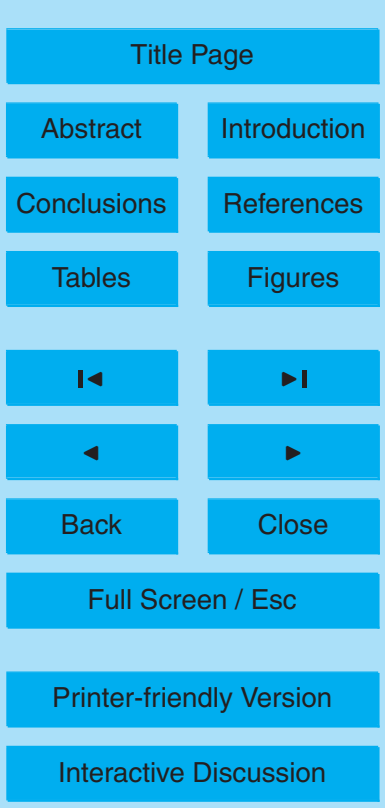




\section{Method}

\subsection{Instruments}

Both the Cloud Droplet Probe (CDP) and the Two-Dimensional Stereo (2D-S) collected data during the VOCALS-REx field campaign and were used to find the effective radius

5 and liquid water content of clouds. The CDP measures the size and concentration of cloud droplets nominally between 3 and $50 \mu$ m (Wood et al., 2011; Lance et al., 2010; Rosenberg et al., 2012). The size bins for the data gathered in VOCALS-REx and used in this paper, were adjusted after the recalibration (Wood et al., 2011). The 2D-S measures particles in the size range of $15 \mu \mathrm{m}$ to $2 \mathrm{~mm}$ by imaging the shadows of the particles (Lawson et al., 2006). Only one laser and detector array was used during VOCALS. The shortwave radiometric data was collected using two clear domed pyranometers. The pyranometers are shielded from convection using two domes that also restrict the signal to wavelengths between 0.3 and $3 \mu \mathrm{m}$ (FAAM, 2011).

The radiative albedo error bars were derived from the measurement uncertainties of the upward and downward facing aircraft pyranometers which were taken to be $10 \mathrm{~W} \mathrm{~m}^{-2}$ each. These were in turn based upon calibration curves derived from comparison to UKMO standards. The microphysical albedo contains uncertainties from two major of sources. These are the sample volume uncertainty of the CDP which translates to an uncertainty in absolute concentration and the sizing uncertainty which gives an uncertainty in the droplet radius. We have used an uncertainty of $14 \%$ for the sample volume of the CDP due to instrument-to-instrument optical alignment variations. This is based on the difference between the manufacturer's derived value based on geometry calculations and the experimentally derived value for another CDP by Lance et al. (2010). The diameter uncertainties are based on a calibration made before the VOCALS project using spherical glass beads as calibration particles and are approximately $10 \%$. The different uncertainties are combined using the standard methods for uncorrelated uncertainties based on Eqs. (1-3). When combined with the uncertainty

\section{Albedo properties of clouds observed during VOCALS-REx}

B. Parkes et al.

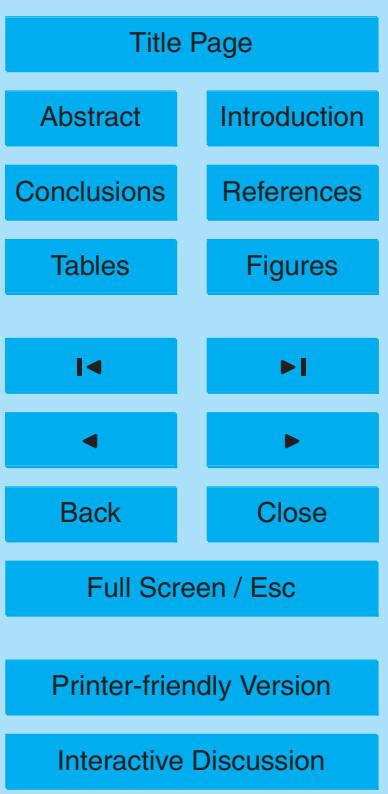


in the cloud thickness (described below) the uncertainty in the microphysical albedo is $20 \%$.

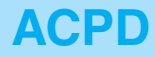

\subsection{Observed data}

The FAAM BAe-146 flew in the stratocumulus clouds on all flights made during the clean cloud segments were selected for further analysis. A clean cloud segment is defined as one where there is little pollution from coastal air parcels. The presence of relatively large amounts of sulphate aerosol in the Aerosol Mass Spectrometer indicated a polluted air parcel from the coast. It was also required that both the CDP and the 2D-S instruments and be free from coastal pollution. Table 1 gives the length of time used, the altitude of the cloud base and the thickness of the cloud segment. Each flight involved ascent into the cloud followed by a straight and level run and finally ascent out of the cloud. The cloud-segment boundaries that defined the start and end times and cloud top and bottom, were determined by using a threshold number of particle counts on the CDP. An example of the data selected for Cloud segment 1 is shown in Fig. 1 where the start and end times and altitudes are shown by the black dashed lines, the altitude of the aircraft is in blue and the analysed section is shown in red. The analysed times for each cloud are shown in Table 1. With the exception of Cloud 1 all flat and levels runs took place in the top third of the cloud.

\subsection{Albedo derivation}

The microphysical albedo derivation was based upon the $\delta$-Eddington approximation detailed in Los and Duynkerke (2001) and shown in Eq. (1). In that equation $\mu_{0}$ is the cosine of the solar zenith angle, $g$ is an asymmetry factor, $\tau$ is the cloud optical depth as described by Equation (2) and $A_{\delta \text {-Edd }}(\tau)$ is the albedo. The value of $g$ set to be $\mathbf{0 . 8 5}$, as suggested by Twohy et al. (2005), as a suitable value for droplets in a clean environment. The derivation of the optical thickness is dependent on the liquid
12, 30021-30037, 2012

\section{Albedo properties of clouds observed during VOCALS-REx}

B. Parkes et al.

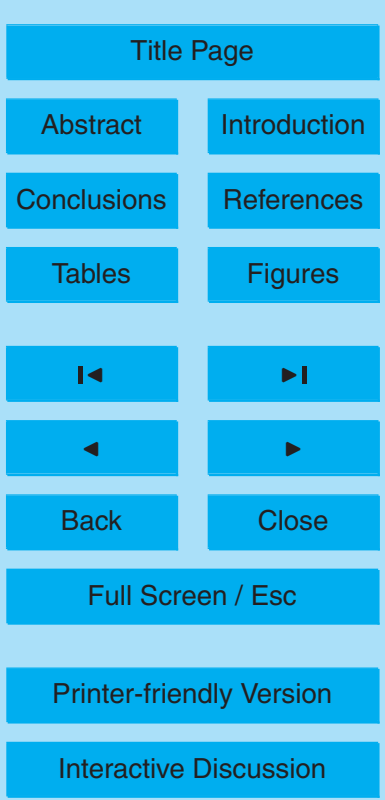


water path (LWP), the density of water $\left(\rho_{\mathrm{w}}\right)$ and the effective radius $\left(r_{\mathrm{e}}\right)$. The method of calculating the effective radius is shown in Eq. (3).

To calculate the cloud albedo using the CDP several assumptions are made, each of which adds uncertainty to the result. The liquid water path is assumed to be the 5 liquid water content multiplied by the cloud thickness below the aircraft (Roberts et al., 2008). The liquid water content is recorded at a rate of $1 \mathrm{~Hz}$ by the CDP and the mean from ten seconds of data is used to give the value plotted. The uncertainty in the liquid water path, both from the liquid water path and the relative position of the aircraft to the top and bottom of the cloud is assumed to be $10 \%$. The flight legs are about $10 \mathrm{~min}$ 10 each in segment from the flight on the 9 November 2008 and 20 min each in segment from the flight on 12 November 2008. The shortwave albedo is calculated by taking the ratio of upwelling to downwelling shortwave radiation recorded by two clear-domed pyranometers mounted facing down and up from the aircraft.

$A_{\delta-\mathrm{Edd}}(\tau)=1-\frac{\left(2+3 \mu_{0}\right)+\left(2-3 \mu_{0}\right) e^{-\tau\left(1-g^{2}\right) / \mu_{0}}}{4+3(1-g) \tau}$

$\tau=\frac{3 \mathrm{LWP}}{2 \rho_{w} r_{\mathrm{e}}}$

$r_{\mathrm{e}}=\frac{\int_{r_{1}}^{r_{2}} \pi r^{3} n(r) d r}{\int_{r_{1}}^{r_{2}} \pi r^{2} n(r) d r}$

\section{Albedo properties of clouds observed during VOCALS-REx}

B. Parkes et al.

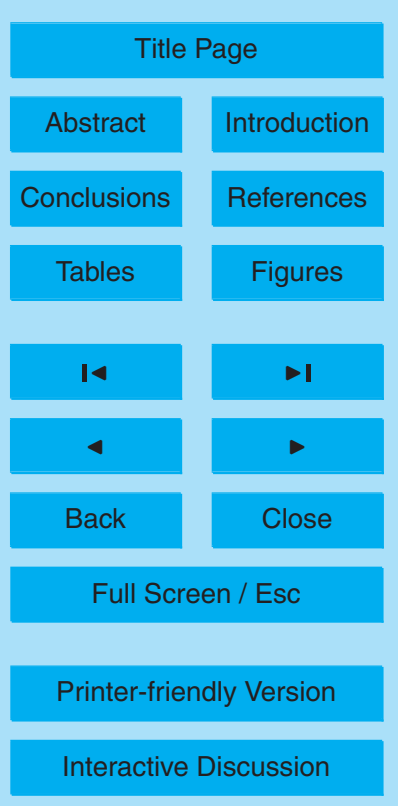




\section{Results}

\subsection{Effective radius}

The relative contribution of the 2D-S and the CDP to the effective radius was investigated. It was found that the droplets observed by the 2D-S had little impact on the ef-

5 fective radius and therefore the result from the 2D-S were no longer used. Henceforth the CDP was used as the source for microphysical data. Figure 2 shows the relation between the effective radius and the radiometric shortwave albedo. There appears to be two regimes in the relationship between shortwave albedo and effective radius, below $18 \mu \mathrm{m}$ there is an increase in albedo with increasing effective radius, above this 10 value the albedo reaches a plateau.

\subsection{Liquid water path}

The liquid water path (LWP) is calculated using data from the CDP by multiplying the liquid water content (LWC) by the cloud thickness, using the assumption that the LWP is constant throughout the cloud (Stephens, 1978). Figure 3 shows the ten-second 15 mean LWP from four clean cloud segments plotted against the shortwave albedo. The results shown in Fig. 3 are similar to the results from the WENPEX field campaign in Japan, detailed in Fujiyoshi et al. (1995) and a field campaign in turreted clouds off the eastern coast of Australia, detailed in Paltridge (1974). The results in Fig. 3 show a similar trend to those in Fig. 2 where the shortwave albedo increases with LWP up to a LWP of $250 \mathrm{~g} \mathrm{~m}^{-2}$ after which there is a plateau.

\subsection{Albedo comparisons}

A comparison between the shortwave albedo and the microphysical albedo from the four clean cloud segments defined in Table 1 is shown in Fig. 4. The correlation between the results is poor with an $R^{2}$ value of 0.51 . In addition to the poor correla-

\section{Albedo properties of clouds observed during VOCALS-REx}

B. Parkes et al.

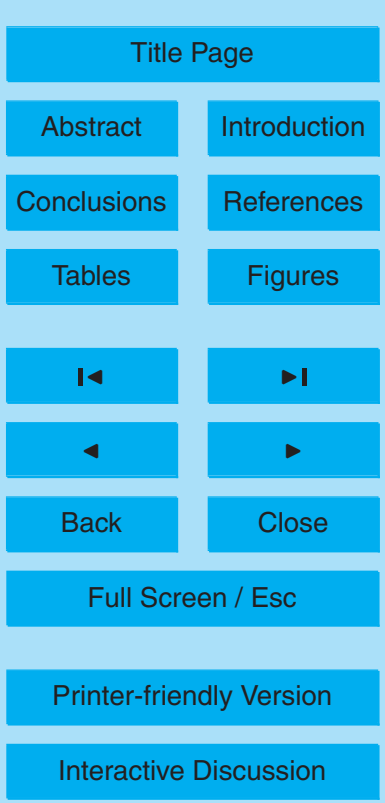

Interactive Discussion 
significantly different from the other three clouds. A plot of the ratio of microphysical to shortwave albedo against the solar zenith angle was produced to investigate the impacts of the high solar zenith angles (See Fig. 5). The results from Fig. 5 show significant variance in the albedo for Cloud segment 1 . The $\delta$-Eddington approximation 5 appears to break down for solar zenith angles over 65 degrees. In this region it is possible that side scattering is more important than forward and backward scattering. This is possible because incoming radiation is now striking the droplets obliquely with respect to the aircraft. In the light of the results in Fig. 5, Cloud segment 1 has been removed from further analysis.

10 The results in Fig. 4 when Cloud segment 1 is dismissed shows an improved $R^{2}$ correlation of 0.78 . This indicates that for Cloud segments $2-4$ it is appropriate to use the $\delta$-Eddington approximation to calculate the shortwave albedo.

\section{Conclusions}

In this work we have shown the microphysical and optical shortwave albedo from four 15 clean cloud segments observed during the VOCALS-REx field campaign. Each of the clouds were required to have good CDP and radiometric data with satellite coverage and contain little to no coastal pollution. The assumption that the LWP can be calculated by multiplying the LWC by the cloud thickness was justified since the results from Fig. 3 are in good agreement with previous experimental results.

$20 \quad$ The results from Fig. 4 and Fig. 5 indicate that the $\delta$-Eddington approximation cannot be used as a method for finding the shortwave albedo of clouds in all circumstances. However the results from Fig. 4 when Cloud segment 1 is ignored show that it is suitable for solar zenith angles below approximately 65 degrees $\left(\mu_{0}=0.42\right)$ where the $R^{2}$ improves to 0.78 . The results in this work show that the $\delta$-Eddington approximation is suitable for solar zenith angles below 65 degrees and this agrees well with the theoretical work in Joseph et al. (1976).

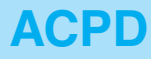

12, 30021-30037, 2012

\section{Albedo properties of clouds observed during VOCALS-REx}

B. Parkes et al.

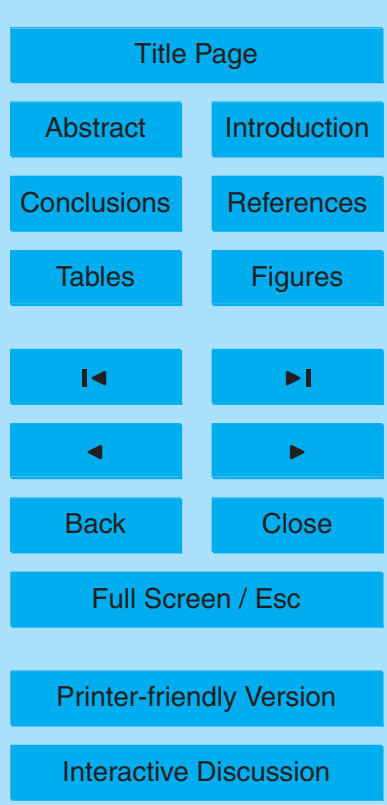


Acknowledgements. This work made use of data provided by NCAR/EOL under sponsorship of the National Science Foundation and the British Atmospheric Data Centre (BADC) which is the Natural Environment Research Council's (NERC) Designated Data Centre for the Atmospheric Sciences. The authors would also like to extend their thanks to the University of Manchester 5 (UK). Support for this research was provided by the Fund for Innovative Climate and Energy Research, FICER, at the University of Calgary. Airborne data was obtained using the BAe146-301 Atmospheric Research Aircraft [ARA] flown by Directflight Ltd and managed by the Facility for Airborne Atmospheric Measurements [FAAM], which is a joint entity of the Natural Environment Research Council [NERC] and the Met Office.

\section{References}

Borg, L. A. and Bennartz, R.: Vertical structure of stratiform marine boundary layer clouds and its impact on cloud albedo, Geophys. Res. Lett., 34, L05807, available at: http://www.agu. org/journals/gl/gl0705/2006GL028713/2006GL028713.pdf, 2007. 30022

Bretherton, C. S., Wood, R., George, R. C., Leon, D., Allen, G., and Zheng, X.: Southeast Pacific stratocumulus clouds, precipitation and boundary layer structure sampled along $20^{\circ} \mathrm{S}$ during VOCALS-REx, Atmos. Chem. Phys., 10, 10639-10654, doi:10.5194/acp-10-106392010, 2010. 30023

FAAM: Broadband Radiometers, Tech. rep., Faculty of Airborne Atmopsheric Measurement, 2011. 30024

Fujiyoshi, Y., Ishizaka, Y., Takeda, T., Hayasaka, T., and Tanaka, M.: Measurement of Vertical Liquid Water Path by Means of an Airborne Radiometer and the Shortwave Albedo of Marine Low-Level Clouds during WENPEX in Japan, J. Appl. Meteorol., 34, 471-481, doi:10.1175/1520-0450-34.2.471, 1995. 30027

Hanson, H. P.: Marine stratocumulus climatologies, Int. J. Climatol., 11, 147-164, doi:10.1002/joc.3370110204, 1991. 30022

Joseph, J. H., Wiscombe, W. J., and Weinman, J. A.: The Delta-Eddington Approximation for Radiative Flux Transfer, J. Atmos. Sci., 33, 2452-2459, doi:10.1175/15200469(1976)033<2452:TDEAFR>2.0.CO;2, 1976. 30023, 30028 
Lance, S., Brock, C. A., Rogers, D., and Gordon, J. A.: Water droplet calibration of the Cloud Droplet Probe (CDP) and in-flight performance in liquid, ice and mixed-phase clouds during ARCPAC, Atmos. Meas. Tech., 3, 1683-1706, doi:10.5194/amt-3-1683-2010, 2010. 30024

Lawson, R. P., O'Connor, D., Zmarzly, P., Weaver, K., Baker, B., Mo, Q., and Jonsson, $5 \quad$ H.: The 2D-S (Stereo) Probe: Design and Preliminary Tests of a New Airborne, HighSpeed, High-Resolution Particle Imaging Probe, J. Atmos. Ocean. Tech., 23, 1462-1477, doi:10.1175/JTECH1927.1, 2006. 30024

Los, A. and Duynkerke, P. G.: Parametrization of solar radiation in inhomogeneous stratocumulus: Albedo bias, Q. J. Roy. Meteor. Soc., 127, 1593-1614, doi:10.1002/qj.49712757507, 2001. 30023, 30025

Meador, W. E. and Weaver, W. R.: Two-Stream Approximations to Radiative Transfer in Planetary Atmospheres: A Unified Description of Existing Methods and a New Improvement, J. Atmos. Sci., 37, 630-643, doi:10.1175/1520-0469(1980)037;0630:TSATRT ¿2.0.CO;2, 1980. 30023

Paltridge, G. W.: Infrared emissivity, short-wave albedo, and the microphysics of stratiform water clouds, J. Geophys. Res., 79, 4053-4058, 1974. 30027

Roberts, G. C., Ramana, M. V., Corrigan, C., Kim, D., and Ramanathan, V.: Simultaneous observations of aerosol-cloud-albedo interactions with three stacked unmanned aerial vehicles, Proceedings of the National Academy of Sciences, 105, 7370-7375, http://www.pnas. org/content/105/21/7370.abstract, 2008. 30023, 30026

Rosenberg, P. D., Dean, A. R., Williams, P. I., Dorsey, J. R., Minikin, A., Pickering, M. A., and Petzold, A.: Particle sizing calibration with refractive index correction for light scattering optical particle counters and impacts upon PCASP and CDP data collected during the Fennec campaign, Atmos. Meas. Tech., 5, 1147-1163, doi:10.5194/amt-5-1147-2012, 2012. 30024

Stephens, G. L.: Radiation Profiles in Extended Water Clouds. II: Parameterization Schemes, J. Atmos. Sci., 35, 2123-2132, doi:10.1175/1520-0469(1978)035¡2123:RPIEWC ¿2.0.CO;2, 1978. 30027

Twohy, C. H., Petters, M. D., Snider, J. R., Stevens, B., Tahnk, W., Wetzel, M., Russell, L., and Burnet, F.: Evaluation of the aerosol indirect effect in marine stratocumulus clouds: Droplet number, size, liquid water path, and radiative impact, J. Geophys. Res., 110, D08203, available at: http://aerosols.ucsd.edu/papers/Twohy2005jgr.pdf, 2005. 30023, 30025

\section{Albedo properties of clouds observed during VOCALS-REx}

B. Parkes et al.

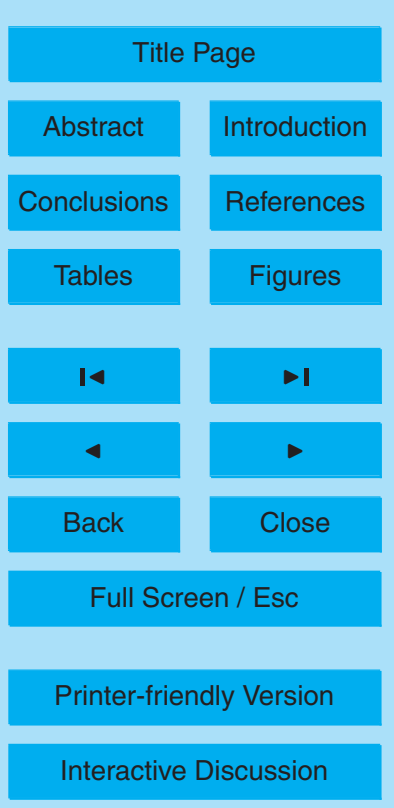


Van-Weele, M. and Duynkerke, P. G.: Effect of clouds on the photodissociation of $\mathrm{NO}_{2}$ : Observations and modelling, J. Atmos. Chem., 16, 231-255, doi:10.1007/BF00696898, 1993. 30023

Wang, H., Feingold, G., Wood, R., and Kazil, J.: Modelling microphysical and meteorological controls on precipitation and cloud cellular structures in Southeast Pacific stratocumulus, Atmos. Chem. Phys., 10, 6347-6362, doi:10.5194/acp-10-6347-2010, 2010. 30023

Wood, R., Mechoso, C. R., Bretherton, C. S., Weller, R. A., Huebert, B., Straneo, F., Albrecht, B. A., Coe, H., Allen, G., Vaughan, G., Daum, P., Fairall, C., Chand, D., Gallardo Klenner, L., Garreaud, R., Grados, C., Covert, D. S., Bates, T. S., Krejci, R., Russell, L. M., de Szoeke, S., Brewer, A., Yuter, S. E., Springston, S. R., Chaigneau, A., Toniazzo, T., Minnis, P., Palikonda, R., Abel, S. J., Brown, W. O. J., Williams, S., Fochesatto, J., Brioude, J., and Bower, K. N.: The VAMOS Ocean-Cloud-Atmosphere-Land Study Regional Experiment (VOCALS-REx): goals, platforms, and field operations, Atmos. Chem. Phys., 11, 627-654, doi:10.5194/acp11-627-2011, 2011. 30022, 30024

\section{ACPD}

12, 30021-30037, 2012

\section{Albedo properties of clouds observed during VOCALS-REx}

B. Parkes et al.

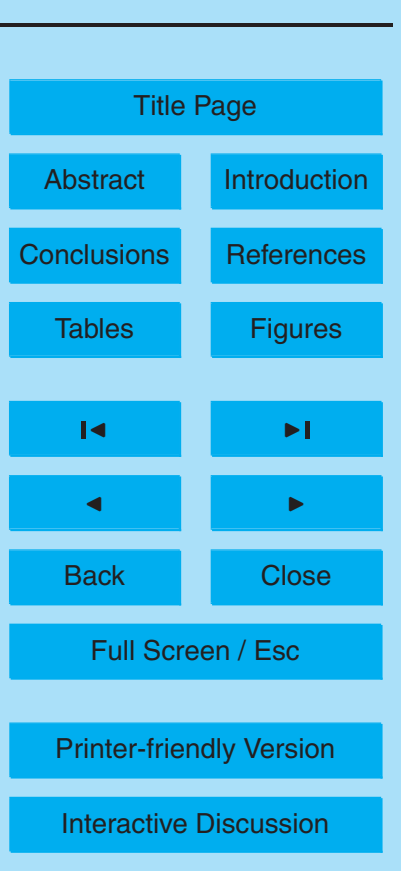




\section{ACPD}

12, 30021-30037, 2012

\section{Albedo properties of clouds observed during VOCALS-REx}
B. Parkes et al.

Table 1. Four clean cloud segments observed during the VOCALS-REx field campaign.

\begin{tabular}{lrrrr}
\hline & $\begin{array}{r}\text { Start time } \\
(\text { UTC) }\end{array}$ & $\begin{array}{r}\text { End time } \\
(\mathrm{UTC})\end{array}$ & $\begin{array}{r}\text { Thickness } \\
(\mathrm{m})\end{array}$ & $\begin{array}{r}\text { Cloud base } \\
(\mathrm{m})\end{array}$ \\
\hline Cloud segment 1 & $11: 58: 23$ & $12: 07: 41$ & 464.6 & 974.8 \\
Cloud segment 2 & $12: 40: 41$ & $12: 50: 44$ & 523.1 & 940.3 \\
Cloud segment 3 & $13: 02: 01$ & $13: 22: 06$ & 402.3 & 812.4 \\
Cloud segment 4 & $13: 37: 21$ & $13: 57: 31$ & 428.2 & 804.0 \\
\hline
\end{tabular}

Title Page

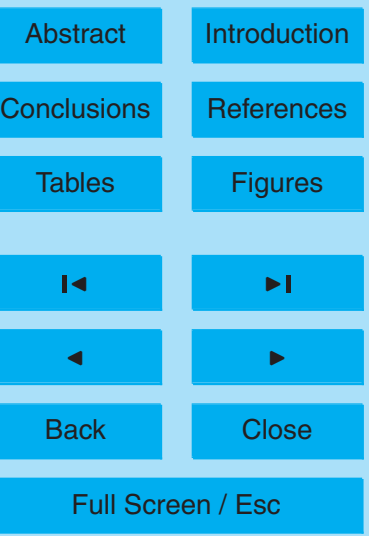

Printer-friendly Version

Interactive Discussion 


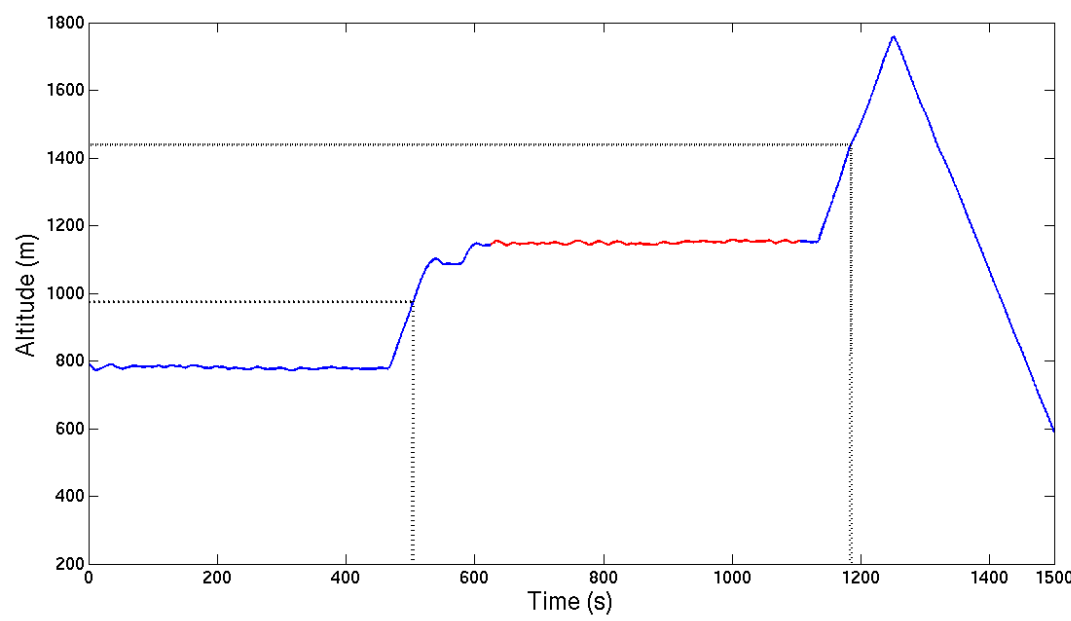

Fig. 1. Altitude of the FAAM BAe-146 from a section from the flight on 26th October 2008, where the rejected periods are in blue, the time analysed as Cloud 1 is in red and the black dashed lines show the start and end time of the in cloud leg defined by CDP activity.

\section{ACPD}

12, 30021-30037, 2012

\section{Albedo properties of clouds observed during VOCALS-REx}

B. Parkes et al.

\section{Title Page}

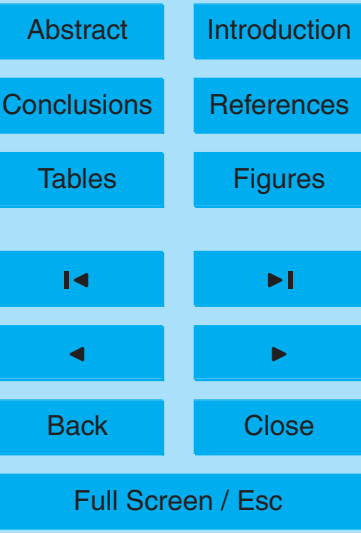

Printer-friendly Version

Interactive Discussion 


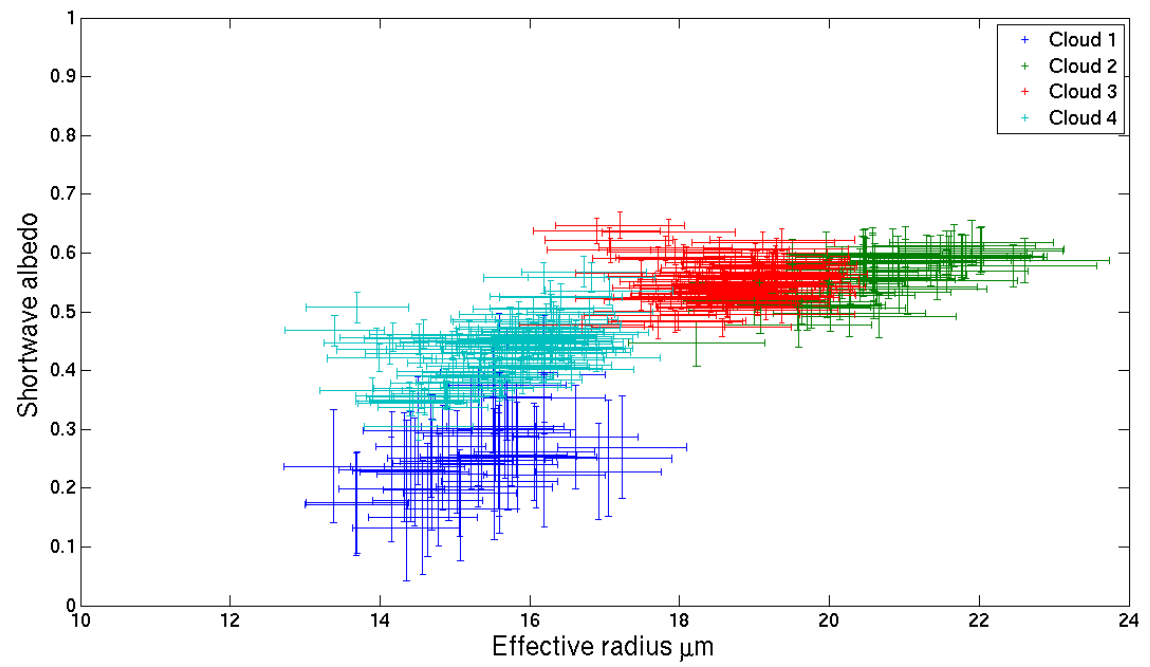

Fig. 2. The ten second mean effective radius $(\mu \mathrm{m})$ against the shortwave radiometric albedo for four clean cloud segments identified during the VOCALS-REx field campaign. The error bars are the mean of the uncertainties which were calculated for each measured value.

\section{ACPD}

12, 30021-30037, 2012

\section{Albedo properties of clouds observed during VOCALS-REx}

B. Parkes et al.

Title Page

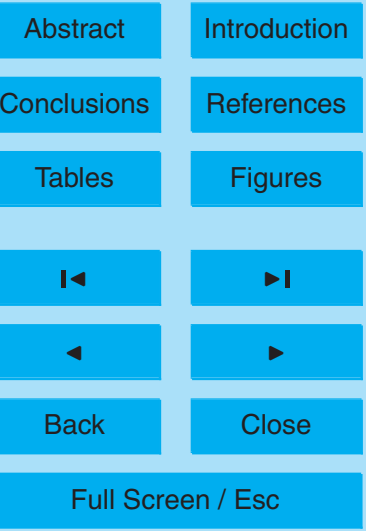

Printer-friendly Version

Interactive Discussion 


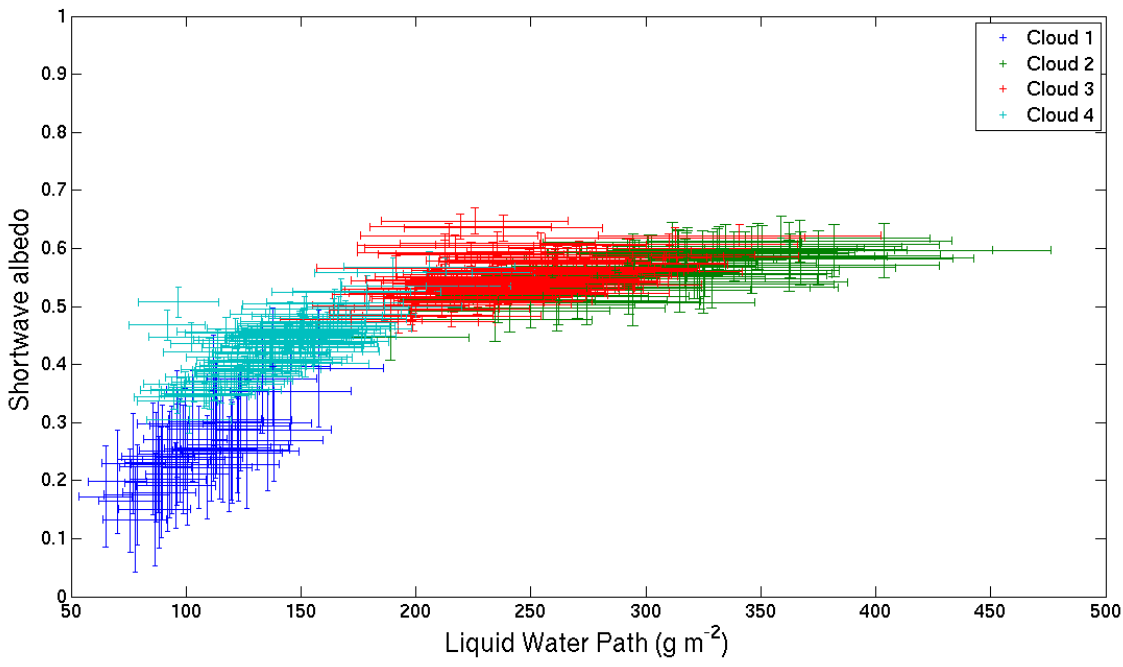

Fig. 3. The ten second mean liquid water path $\left(\mathrm{gm}^{-2}\right)$ against the shortwave radiometric albedo for four clean cloud segments identified during the VOCALS-REx field campaign. The error bars are the mean of the uncertainties which were calculated for each measured value.
ACPD

12, 30021-30037, 2012

\section{Albedo properties of clouds observed during VOCALS-REx}

B. Parkes et al.

\section{Title Page}

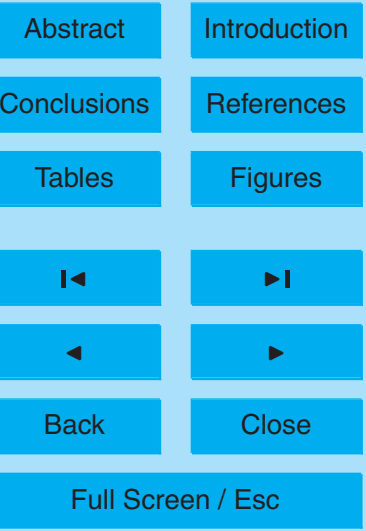

Printer-friendly Version

Interactive Discussion 


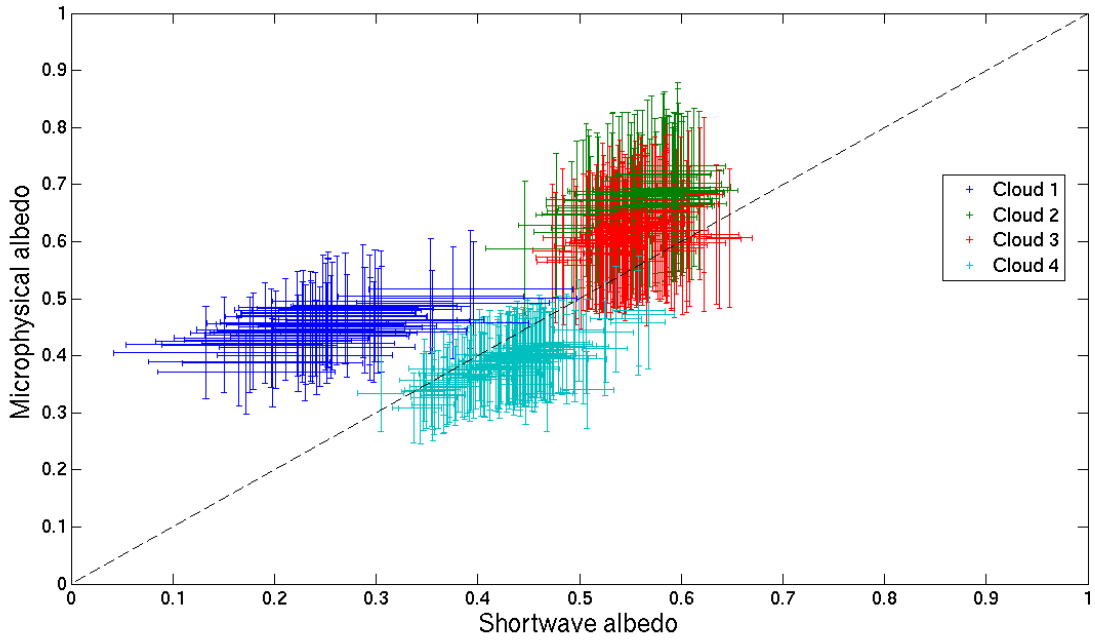

Fig. 4. Albedo comparison for four clean cloud segments observed during the VOCALS-REx field campaign. The error bars are the mean of the uncertainties which were calculated for each measured value. A 1:1 line is shown in by the dashed black line.

\section{Albedo properties of clouds observed during VOCALS-REx}
B. Parkes et al.

Title Page

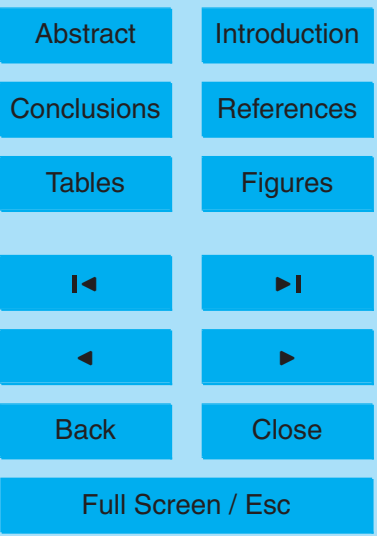

Printer-friendly Version

Interactive Discussion 


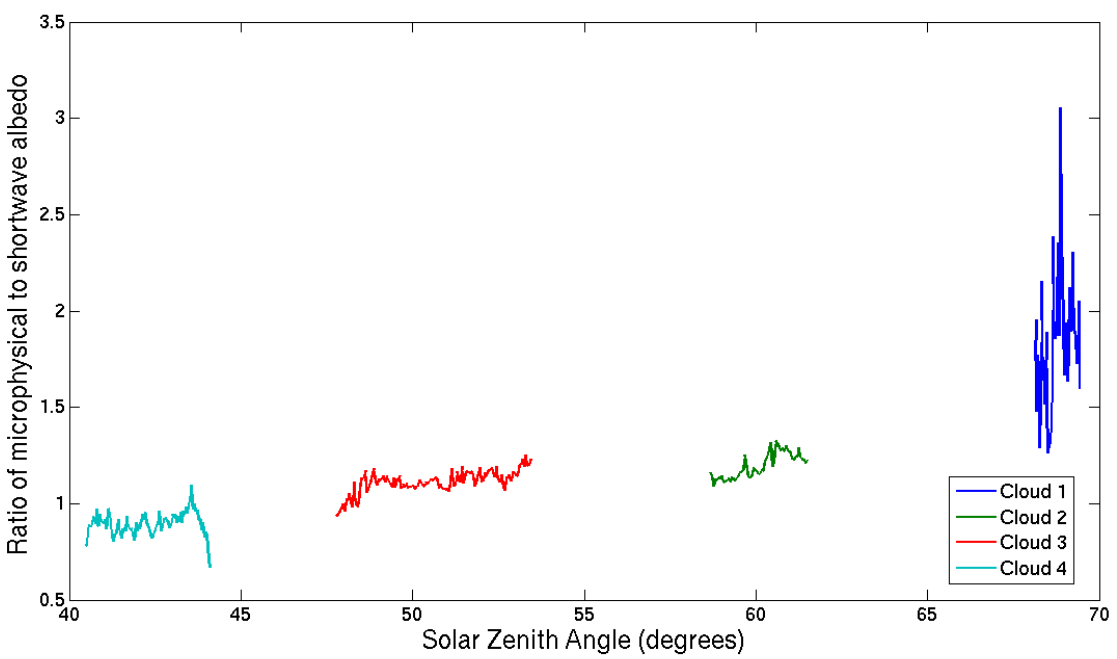

ACPD

12, 30021-30037, 2012

Albedo properties of clouds observed during VOCALS-REx

B. Parkes et al.

Title Page

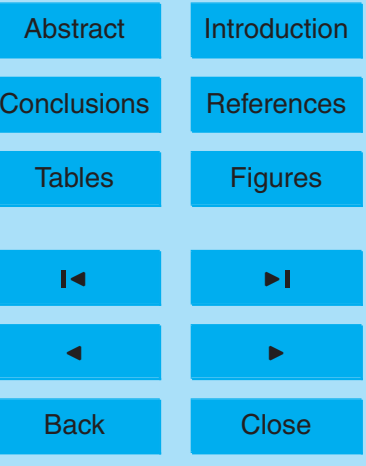

Full Screen / Esc

Fig. 5. The ratio of microphysical to shortwave albedo plotted against solar zenith angle from the FAAM BAe-146.

Printer-friendly Version

Interactive Discussion 